\title{
Publisher Correction: A deep-learning technique for phase identification in multiphase inorganic compounds using synthetic XRD powder patterns
}

\author{
Jin-Woong Lee, Woon Bae Park, Jin Hee Lee, Satendra Pal Singh (D) \& Kee-Sun Sohn (1)
}

Correction to: Nature Communications https://doi.org/10.1038/s41467-019-13749-3, published online 03 January 2020.

The original version of this Article contained an error in the second sentence of the Abstract, which incorrectly read 'We simulate plausible powder X-ray powder diffraction (XRD) patterns.' The correct version removes 'powder' before 'diffraction'.

The original version of this Article contained an error in the first sentence of the Introduction, which incorrectly read 'We have recently discovered many novel inorganic functional materials by employing powder X-ray powder diffraction (XRD) analysis.' The correct version removes 'powder' before 'diffraction'.

The original version of this article also contained an error in the last sentence of the third paragraph of the 'Real data test' section of the Results, which incorrectly read 'Basic bending of real pure sample XRD patterns would still be insufficient to simulate real-world samples, although they should be, of course, definitely superior to computer-simulated patterns.' The correct version states 'blending' in place of 'bending'.

These have been corrected in both the PDF and HTML versions of the Article.

Published online: 30 January 2020

Open Access This article is licensed under a Creative Commons Attribution 4.0 International License, which permits use, sharing, adaptation, distribution and reproduction in any medium or format, as long as you give appropriate credit to the original author(s) and the source, provide a link to the Creative Commons license, and indicate if changes were made. The images or other third party material in this article are included in the article's Creative Commons license, unless indicated otherwise in a credit line to the material. If material is not included in the article's Creative Commons license and your intended use is not permitted by statutory regulation or exceeds the permitted use, you will need to obtain permission directly from the copyright holder. To view a copy of this license, visit http://creativecommons.org/licenses/by/4.0/.
}

(C) The Author(s) 2020 